\title{
Scientific Evaluation and Pricing of Medical Devices and Associated Procedures in France
}

\author{
Martine Gilard ${ }^{1}$, Frédérique Debroucker ${ }^{2}$, Claude Dubray ${ }^{3}$ and participants of round table $N^{\circ} 1$ of Giens \\ Workshops XXVIII: Yves Allioux ${ }^{4}$, Eliane Aper ${ }^{5}$, Valérie Barat-Leonhardt ${ }^{6}$, Michèle Brami ${ }^{7}$, Cédric Carbonneil ${ }^{8}$, \\ Emmanuel Chartier-Kastler ${ }^{9}$, Claire Coqueblin ${ }^{10}$, Sandrine Fare ${ }^{11}$, Isabelle Giri ${ }^{12}$, Jean-Marie Goehrs ${ }^{13}$,
} Karine Levesque ${ }^{14}$, Philippe Maugendre ${ }^{15}$, François Parquin ${ }^{16}$, Jean-Patrick Sales ${ }^{17}$ and Karine Szwarcensztein ${ }^{18}{ }^{\dagger}$

1 Centre Hospitalier Universitaire La Cavale Blanche, Brest, France

2 Medtronic France, Boulogne-Billancourt, France

3 Centre de Pharmacologie Clinique, Clermont-Ferrand, France

4 CNAMTS, Paris, France

5 General Electric, Vélizy, France

6 GlaxoSmithKline, Marly-le-Roi, France

7 Agence Technique de l'Information sur l'Hospitalisation, Paris, France

8 Direction générale de l'Offre de Soins, Paris, France

9 Hôpital Pitié-Salpêtrière, Paris, France

10 DGCIS, Ivry, France

11 Direction de la Sécurité sociale, Paris, France

12 Access Conseil, Paris, France

13 JMGoehrs Partners, Versailles, France

14 Abbott Vascular, Rungis, France

15 Sanofi Aventis, Paris, France

16 Hôpital Foch, Boulogne-Billancourt, France

17 Haute Autorité de Santé, Saint-Denis La Plaine, France

18 Johnson \& Johnson, Issy-les-Moulineaux, France

Text received March $15^{\text {th }}, 2013$; accepted $7^{\text {th }}$ May, 2013

\section{Keywords:}

medical devices; medical procedure; evaluation; price; funding; reimbursement

\begin{abstract}
Medical devices are many and various, ranging from tongue spatulas to implantable or invasive devices and imaging machines; their lifetimes are short, between 18 months and 5 years, due to incessant incremental innovation; and they are operator-dependent: in general, the clinical user performs a fitting procedure (hip implant or pacemaker), a therapeutic procedure using a non-implantable invasive device (arrhythmic site ablation probe, angioplasty balloon, extension spondyloplasty system, etc.) or follow-up of an active implanted device (long-term follow-up of an implanted cardiac defibrillator or of a deep brain stimulator in Parkinson's patients).

A round-table held during the XXVIII ${ }^{\text {th }}$ Giens Workshops meeting focused on the methodology of scientific evaluation of medical devices and the associated procedures with a view to their pricing and financing by the French National Health Insurance system. The working hypothesis was that the available data-set was sufficient for and compatible with scientific evaluation with clinical benefit. Post-registration studies, although contributing to the continuity of assessment, were not dealt with. Moreover, the focus was restricted to devices used in health establishments, where the association between devices and technical medical procedures is optimally representative.

An update of the multiple regulatory protocols governing medical devices and procedures is provided. Issues more specifically related to procedures as such, to non-implantable devices and to innovative devices are then dealt with, and the proposals and discussion points raised at the round-table for each of these three areas are presented.
\end{abstract}

Abbreviations: see end of article.

\footnotetext{
${ }^{\dagger}$ Articles, analyzes and proposals from the Giens workshops are those of the authors and do not prejudice the position of their parent organization.
} 


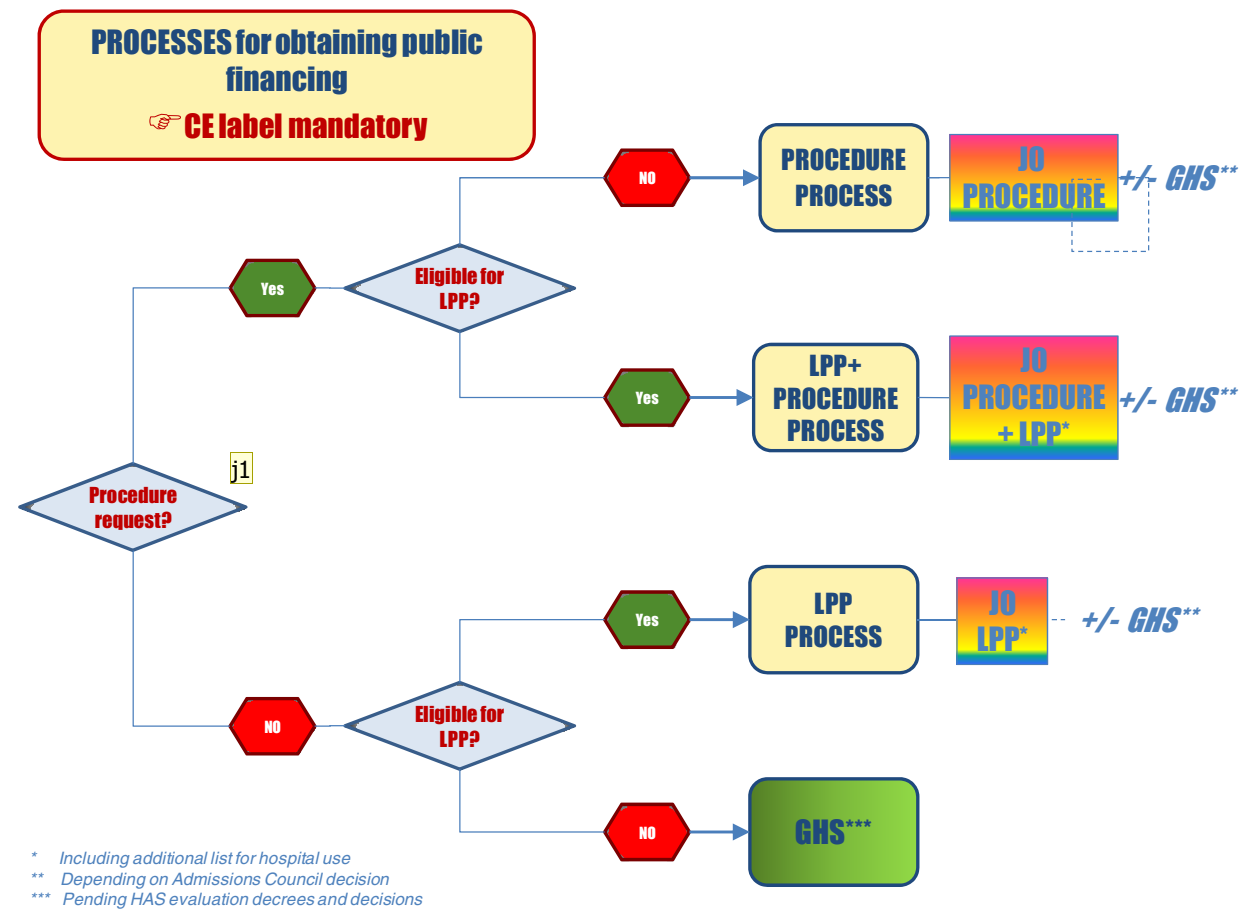

Fig. 1. Processes of evaluation and pricing for public financing of medical devices and associated procedures.

GHS: admission-related group (groupe homogène de malades); JO: french official laws journal (Journal officiel); LPP: list of products and services reimbursed by the National Health Insurance System (liste des produits et prestations remboursables).

\section{Background}

Evaluation and pricing of medical devices and the associated procedures in France is multiform and complex (figure 1). It is based on two underlying questions:

- For the device to be able to be used, does a technical procedure item not already listed in the various nomenclatures (medical procedures classification [classification commune des actes médicaux or CCAM], general professional procedures nomenclature [nomenclature générale des actes professionnels or NGAP], medical biology procedures nomenclature [nomenclature des actes de biologie médicale or NABM) need to be created?

If so, a request should be made to the French Health Authority (Haute autorité de santé [HAS]) to have the procedure scientifically assessed, either by the scientific society or societies concerned (using a form that comprises a few pages) or by the Ministry of Health or by the National Union of Health Insurance Payment Offices (Union nationale des caisses d'Assurance maladie [UNCAM]). In the first of these three cases, registration of the application on the HAS work schedule is, as will be seen below, not automatic.

The procedure is then priced, on the basis of advice provided by the HAS College, by the nomenclature office of the UNCAM, after negotiation with health professionals.

- Does the device meet the eligibility conditions set out in the list of products and services reimbursed by the National health insurance system (liste des produits et prestations remboursables [LPP]) and defined in article 165-1 of the national health insurance code (Code de la sécurité sociale [CSS]) [annex 1] ${ }^{[1]}$

If so, either there already exists a rubric under which the manufacturer can register the device in the LPP, or else the manufacturer will have to submit a complete "brand name" registration request file to the specialized National Medical Device and Health Technology Evaluation Commission (Commission nationale d'évaluation des dispositifs médicaux et des technologies de santé [CNEDiMTS]) of the HAS and the Health Products Economic Committee (Comité économique des produits de santé [CEPS]) [annex 2].

The CNEDiMTS performs a scientific evaluation of the device on the basis of available information. Pricing is determined by the CEPS on the basis of the CNEDiMTS's advice, after negotiation with the manufacturer.

Implantable medical devices used in health establishments can be registered both in the LPP list and in the "additional" list, so as to be financed "additionally" to the fixed GHS admission price; this can only be done once the Hospital Admission Council has given a positive opinion as to the resultant heterogeneity of the hospital care, the costs involved and the means of use of the device (annex 2).

The entire evaluation and pricing procedure is subject to a regulatory minimum period of 180 days; in practice, a new LPP registration for a medical device takes on average some 9 months overall, with the CNEDiMTS evaluation taking a mean 85 days in 2011. 
If the answer to both above questions is "yes", then a 2-fold procedure is implemented. When the manufacturer submits the application file, the HAS undertakes an evaluation of the associated procedure, based on the file, with input from an ad hoc working group as necessary. Thus, evaluation of the associated procedure is "tied in" to the evaluation of the device.

Finally, for medical devices not eligible for LPP listing and which therefore come under intra-admission related group (groupe homogène de malades [GHS]) pricing, the treatment may be scientifically assessed by evaluation of the procedure if there is no preexisting evaluation or, if appropriate, as part of the next intra-GHS device categories evaluation as per article 165-11 of the National Health Insurance code (Code de la sécurité sociale $[\mathrm{CSS}])^{[2]}$ under the Drugs and Health Products Safety Reinforcement law of December 21, 2011, in which case the device is financed out of the GHS admission charges.

Even so, it remains possible for the manufacturer to apply for LPP listing for a product falling under a category already included in the GHS.

\section{Procedures}

Table I presents the steps involved in evaluation and pricing of procedures.

This table shows the complexity and thoroughness of the scientific evaluation performed by the HAS, analyzing the literature and seeking a scientific consensus among the various health professionals concerned. It also shows the large number of those involved in the UNCAM's procedure classification and pricing and the numerous rather obscure steps. Moreover, the regulations impose few deadlines for these various steps.

Finally, throughout the entire procedure, the manufacturer making the application plays no role whatsoever and is not officially recognized as being involved in any way.

The present situation is thus rather imprecise and dependent on the situations that may occur.

Regarding the HAS evaluation:

- when requested by the UNCAM, the process is predetermined and the schedule is structured and predictable;

- when the procedure is tied in to an LPP-listed device, evaluation is based at least on the manufacturer's data. Again, the process is predetermined and the schedule follows that of the evaluation of the device;

- the case of "companion biomarkers" (biomarkers the assessment of which by a diagnostic procedure is required for prescription of a drug under its market authorization) is more complex. When evaluation (assessment of therapeutic interest [note d'intérêt thérapeutique]) of a targeted therapy is requested from the HAS, information regarding the companion biomarker or diagnostic test is included in the request file; but, to date, this does not in itself lead to the associated diagnostic procedure being evaluated. Evaluation is complicated by the fact that two distinct and different objects (drug and diagnostic procedure) are to be evaluated by distinct entities and processes. Moreover, the manufacturers involved in the drug and in the diagnostic procedure are often not the same, and the data required for the latter remain to be clearly defined. Evaluation involves not only the intrinsic performance of the test but also its impact on treatment strategy and other sampling parameters. In oncology, other instances, such as the National Cancer Institute (Institut national du cancer [INCa]) may initially carry out testing so as to make targeted cancer drugs available for patients nationwide via molecular biology platforms. As the INCa has its own hospital clinical research programs (programme hospitalier de recherche clinique [PHRC]) and cost-heavy innovative techniques support programs (programme de soutien aux techniques innovantes et coûteuses [PSTIC]), integrating the INCa/STIC platforms would be especially helpful in providing data to back up evaluation of targeted therapies and their companion tests;

- finally, evaluating the procedure "as such", whether or not associated with a non-LPP device, depends on whether the HAS is able to include the evaluation in its work schedule: no procedure submitted by any scientific society or societies was dealt with in 2012; in 2013, out of 54 applications made by scientific societies (of which only less than a half actually concerned assessment of a technical procedure) only 4 procedures (at most) will be able to be evaluated and 2 will receive detailed analysis to back up a future application.

Regarding the UNCAM classification:

- the various stages are predetermined, but very numerous, and without any regulatory schedule;

- the number of agents involved adds to the complexity of this

- classification phase;

- in the end, there is a real risk of the process seizing up.

Regarding economic assessment and pricing by the UNCAM:

- actual registration following the pricing process is governed by criteria of economic impact that are not in the public domain;

- the final decision of the UNCAM Management College (Collège des directeurs) is not published and there is no provision for appeal.

Finally, although the possibility of attaching a procedure to an LPP medical device has in fact led to coverage being granted within a reasonable time for a few procedures associated to devices providing considerable improvement to the expected service ("high-IES" devices), the process can also take several years or indeed prove fruitless.

The round-table's consensus proposals for procedure evaluation and pricing are as follows:

- the charge-book for applications for procedures "as such" and for non-LPP devices should be more clearly defined, so that 
Table I. Procedure evaluation and pricing.

\begin{tabular}{|c|c|c|c|}
\hline Step & Agents & Actions & Time \\
\hline \multirow[t]{5}{*}{ Application to HAS } & Scientific societies & Form comprising a few pages & \multirow{3}{*}{$\begin{array}{l}\text { Evaluation by HAS according to posi- } \\
\text { tion in work schedule }\end{array}$} \\
\hline & Ministry & Application letter & \\
\hline & INCa & Via Ministry & \\
\hline & UNCAM & Application letter & 180 days, renewable once \\
\hline & HAS itself & For procedure "attached" to a device & $\begin{array}{l}\text { Tied to device evaluation schedule } \\
\text { (extended in case of working group) }\end{array}$ \\
\hline \multirow[t]{4}{*}{$\begin{array}{l}\text { Scientific evaluation by } \\
\text { HAS }\end{array}$} & $\begin{array}{l}\text { SEAP (professional procedures } \\
\text { evaluation dept)/ HAS }\end{array}$ & $\begin{array}{l}\text { 1/ Framing } \\
\text { 2/ Literature analysis } \\
\text { 3/ Reception of expert opinion (working } \\
\text { group(s), reading group, hearing, survey) } \\
\text { Shorter process for procedure attached to } \\
\text { device }\end{array}$ & \multirow[t]{4}{*}{$\begin{array}{l}\text { Other than application to UNCAM, } \\
\text { the HAS is under no regulatory obli- } \\
\text { gation to evaluate submitted proce- } \\
\text { dures. } \\
\text { Procedure evaluation takes an average } \\
\text { 10-14 months after work begins. }\end{array}$} \\
\hline & CNEDiMTS & $\begin{array}{l}\text { 4/ Examination of report and conclusions and } \\
\text { preparation of recommendation }\end{array}$ & \\
\hline & HAS College & 5/ Validation of report and recommendation & \\
\hline & SEAP/ HAS & 6/ Publication & \\
\hline \multirow{4}{*}{$\begin{array}{l}\text { Classification by } \\
\text { UNCAM }\end{array}$} & $\begin{array}{l}\text { Dact (Procedures Management), } \\
\text { scientific societies, ATIH (Techni- } \\
\text { cal Agency for Hospital Admissions } \\
\text { Information) }\end{array}$ & 1/ Proposed titles & \multirow{4}{*}{ No defined schedule } \\
\hline & Expert panel and Dact & 2/ Classification & \\
\hline & Coherence authority & 3/ Validation & \\
\hline & $\begin{array}{l}\text { CHAP (Procedures and services } \\
\text { classification commission) }\end{array}$ & 4/ Classification vote & \\
\hline $\begin{array}{l}\text { UNCAM economic eval- } \\
\text { uation }\end{array}$ & UNCAM & $\begin{array}{l}\text { 1/ Pricing } \\
\text { 2/Evaluation of suitability for registration } \\
\text { 3/Registration conditions }\end{array}$ & No defined schedule \\
\hline \multirow[t]{2}{*}{$\begin{array}{l}\text { Information and consulta- } \\
\text { tion by UNCAM }\end{array}$} & UNCAM & $\begin{array}{l}\text { Letter of intent for Minister, UNPS national } \\
\text { health professionals union, relevant labor } \\
\text { unions, health establishment unions }\end{array}$ & Simple information \\
\hline & $\begin{array}{l}\text { UNOCAM (national union of } \\
\text { complementary health insurance } \\
\text { organizations) }\end{array}$ & Consultation & 6 months, or 21 days if IES I or II \\
\hline Registration by UNCAM & Management College & UNCAM decision & No defined schedule \\
\hline Approval by Minister & Minister & $\begin{array}{l}\text { Possible refusal as of letter of intent and finan- } \\
\text { cial impact }\end{array}$ & $\begin{array}{l}\text { Non-opposition interval of } 45 \text { days, or } \\
15 \text { days if IES I or II }\end{array}$ \\
\hline $\begin{array}{l}\text { Official publication in } \\
\text { (Journal Officiel) }\end{array}$ & UNCAM & Publication according to UNCAM decision & According to UNCAM decision \\
\hline
\end{tabular}

ATIH: Agency for Information Hospital Care (Agence technique de l'information sur l'hospitalisation); CHAP: Procedures and Services Classification Commission (Commission de hiérarchisation des actes et prestations); DM: medical device (dispositif médical); ES: health establishments (établissements de santé); GL: reading group (groupe de lecture); GT: working group (groupe de travail); HAS: Health Authority (Haute autorité de santé); IES: improvement to expected service; SEAP: Professional Procedures Evaluation Department (Service d'évaluation des actes et prestations); UNCAM: National Union of Complementary Health Insurance Organizations (Union nationale des caisses d'Assurance maladie); UNPS: National Union of Health Professionals (Union nationale des professionnels de santé); UNOCAM: National Union of Organizations of supplementary Health Insurance (Union nationale des organismes d'Assurance maladie complémentaires). 
an evaluation application made to the HAS can be properly documented and backed up;

- the HAS's concept of specific evaluation of a procedure for registration should be clarified;

- the manufacturer should be able to contribute legitimately to preparing the application for official recognition of a procedure, and exchanges between manufacturers and scientific societies should be transparent;

- professional bodies should be informed of the evaluation and pricing processes;

- teamwork via professional bodies' Colleges should be increasingly encouraged;

- the processes as a whole should be eased and integrated;

- the HAS's capacity to act should be improved.

Discussion points not definitively adopted by the members of the round table were:

- to transfer responsibility for evaluation to those in charge of the medical device, so as to optimize evaluation while maintaining quality;

- to allow joint application by a manufacturer and a scientific society;

- to encourage input from expert practitioners of the procedure in question, at both the scientific evaluation and classification phases; this would require managing possible relations of interest, whether positive or negative;

- to clarify the UNCAM criteria under which a procedure gets to be registered or not.

\section{3. "Cost-heavy" non-implanted medical devices}

Cost-heavy non-implanted medical devices are a category apart: these are invasive medical devices used during treatment and which do not remain within the patient's body for the 30-day period that would make them eligible for LPP registration under rubric III. The general conditions of the LPP specify that a device can be registered under rubric III only under the following conditions:

1. Total implantation in the human body.

2. Implantation performed only by a physician.

3. Implantation duration exceeding 30 days.

4. Device implantation being the principal objective of the intervention.

Thus the cost or utilization of a non-implanted medical device may introduce heterogeneity in the fixed price of hospital treatment. For example:

- atrial fibrillation site ablation probes;

- intra-uterine endometrium thermocoagulation balloons;

- coronary angiography drug-eluting balloons;

- drug-eluting balloons used in lower-limb obstructive arteriopathy;
- fractional flow-reserve (FFR) measurement during cardiac catheterization.

As these devices are not eligible for the LPP, the HAS's therapeutic benefit assessment, rightly required for any modification of financing, can only be performed via the evaluation of the associated therapeutic procedure where this has not already been done. If the appropriate procedure does already exist, on the other hand, there is no way for the device to be evaluated by the HAS.

These medical devices are financed via the fixed admissionrelated group prices (GHS), defined under the health service pricing by procedure (tarification à l'activité [T2A]), procedure-based pricing system, intended to achieve a case-mix balance: each hospital stay is classified under a diagnosis-related group (GHM) and T2A pays the establishment according to a price, the GHS, calculated on the basis of the mean expenditure reported by the establishments participating in the National Costs Study (étude nationale des coûts à méthodologie commune [ENCC]) for patients in the same diagnosis-related group. The final GHS is adjusted in the light of the costs reported in the ENCC and also other health establishment finance data.

Elements liable to distort the homogeneity of the GHM are financed additionally to the GHS: exceptionally long or shorts stays, intensive care, costly drugs and implantable medical devices. Costheavy non-implantable devices on the other hand were rare at the time the T2A system was set up and have not been provided for.

Moreover, there is no set formula for modifying the GHS according to an evaluation of such devices and associated procedures by the HAS. When the T2A system was set up, however, a given diagnosis-related group was in some rare cases divided into two or more GHS price categories in order to take account of the extra cost incurred by using a costly consumable, and this solution is theoretically available although difficult to implement in practice and very dependent on there being some trace of the use of the costheavy item (e.g., a medical procedures classification [classification commune des actes médicaux] or CCAM code). It is also noteworthy that, while the GHS calculation can take on board the heterogeneity induced by such cost-heavy non-implantable devices, it does so only with a delay of 2 years. Moreover the impact may not be very visible if the device is not being used systematically, as is frequently the case when financing is lacking.

The round table produced only discussion points with respect to these cost-heavy non-implantable devices, also known as "costheavy consumables":

- determine the GHS on the basis of the procedure associated with the device when such exists; this solution should remain exceptional, and the conditions for its implementation remain to be defined (exceptional therapeutic interest, financial impact on the GHS, etc);

- if no specific procedure needs to be created:

- enable a non-LPP device to be registered on the "additional" list, or else review the LPP eligibility criteria (e.g., the 30day implantation threshold), 
- request an intra-GHS evaluation as provided for under Article 165-11 of the National Health Insurance Code according to the "Bertrand" Act of late $2011,{ }^{[2]}$ so as to open a debate on financing in case of exceptional therapeutic interest.

In every case, it is to be stressed that no formula for adapting financing has been defined.

\section{Innovative medical devices}

Innovative medical devices and the associated procedures may in some cases come under the PHRC hospital clinical research program or PSTIC cost-heavy innovative techniques support program, both managed by the general health service authority (Direction générale de l'offre de soins [DGOS]). They are neither necessary or sufficient to guarantee public financing, but do provide a certain help for French centers undertaking certain studies, supplementing clinical data already available with data specific to the French context; these are the data that allow health technology to be evaluated for financing purposes.

The PHRC program notably enables evaluation of a technique's safety and clinical efficacy, by financing comparative studies. The PSTIC program functions downstream of the PHRC or equivalent studies and is intended to validate the clinical and economic interest of a technique with a view to public financing, and is thus upstream of the HAS evaluation. For this reason, the DGOS and HAS decided that the HAS should undertake no evaluation of a technique undergoing PHRC or PSTIC assessment. PHRC and PSTIC submission and selection processes were usefully clarified and structured in 2011.

However, since applications to these programs are made by hospital-based teams, they are not always in line with the international clinical research programs run by the industry, and are in some cases redundant. Implementing a PHRC or PSTIC study may thus introduce considerable delay in HAS health technology evaluation despite the necessary data set being available elsewhere.

Downstream of HAS evaluation, there are several regulatory provisions for innovative techniques.

The forfait innovation, or fixed sum for innovation, introduced under the "Hospitals, Patients, Health and Territories" ("Hôpital, patients, santé, territoire" [HPST]) Act of 2009 (CSS Article 165$1-1),{ }^{[3]}$ provides exceptional temporary financing for innovative technology: innovative products, services and/or procedures for which the HAS has ruled that there is insufficient evidence to justify public financing. The financing depends on the results of a dedicated study, answering the doubts raised in the HAS assessment: i.e., basically a clinical or possibly economic study, focusing on a specific question.

In late 2010, the HAS suggested applying the forfait innovation for several techniques; applications have been ongoing for 2 years, but none so far have been finally accepted.
Article $1151-1$ of the public health code ${ }^{[4]}$ provides a framework for the development or practice of an innovative technique. It is applicable only AFTER an evaluation by the HAS judging the expected service (service attendu [SA]) to be sufficient, and concerns procedures, processes, techniques, diagnostic or therapeutic methods and medical devices. It is implemented when a framework is justified on public health grounds or if the technique is liable to incur unjustified costs. The framework sets out the rules of good practice and technical operating conditions, and the training and qualification of the health professionals involved. Implementation of the technique may be limited to a few health establishments. Article 1151-1 of the public health code was successfully applied in the case of percutaneous aortic cardiac valves.

Finally, if the HAS approves cover by the National Health Insurance scheme but considers further information to be required, registration renewal may be made conditional on the manufacturer performing a post-registration study.

These various programs and regulatory provisions should thus ensure a continuum for innovation, if they are effectively applied, as for example in the case of the forfait innovation (figure 2).

The consensus proposals of the round-table were the following:

- independently of ministerial programs, to ensure coherence with international clinical development plans;

- to implement the

- forfait innovation (art. 165-1-1) rapidly and effectively;

- to ease and integrate the processes.

Finally, on this particular issue of innovative techniques, a disagreement that could not be resolved arose between members of the round-table. An early coding process for innovative technologies was proposed, to deal with the situation whereby a medical device that has obtained a CE label can be used in health establishments in France; this would concern an innovative medical device that has not yet been categorized and registered in the list of intra-GHS categories for HAS evaluation under Article 165-11 of the public health code. $^{[2]}$

As the technology in question is innovative, no associated procedure exists. In point of fact, innovative technologies that have yet to be validated are implemented using procedure codes and GHS codes that are inappropriate, with partial and imperfect financing drawing on the establishment's own budget or provided by the manufacturer. Such non-validated use is not systematic in clinical studies, with the risk that the learning curve required for effective use of the technology may not be in place.

What is at stake is finally more the follow-up of the innovation than its financing as such, since there is no definitive validation and the appropriateness of public financing remains open to question. The aim of early coding, which would very probably be procedurebased, would be to identify the use to which the innovative technology and medical practices is put, to identify patient needs and if possible to assess impact on the basis of existing data-bases and 
Process of validation and financing of medical innovation in France

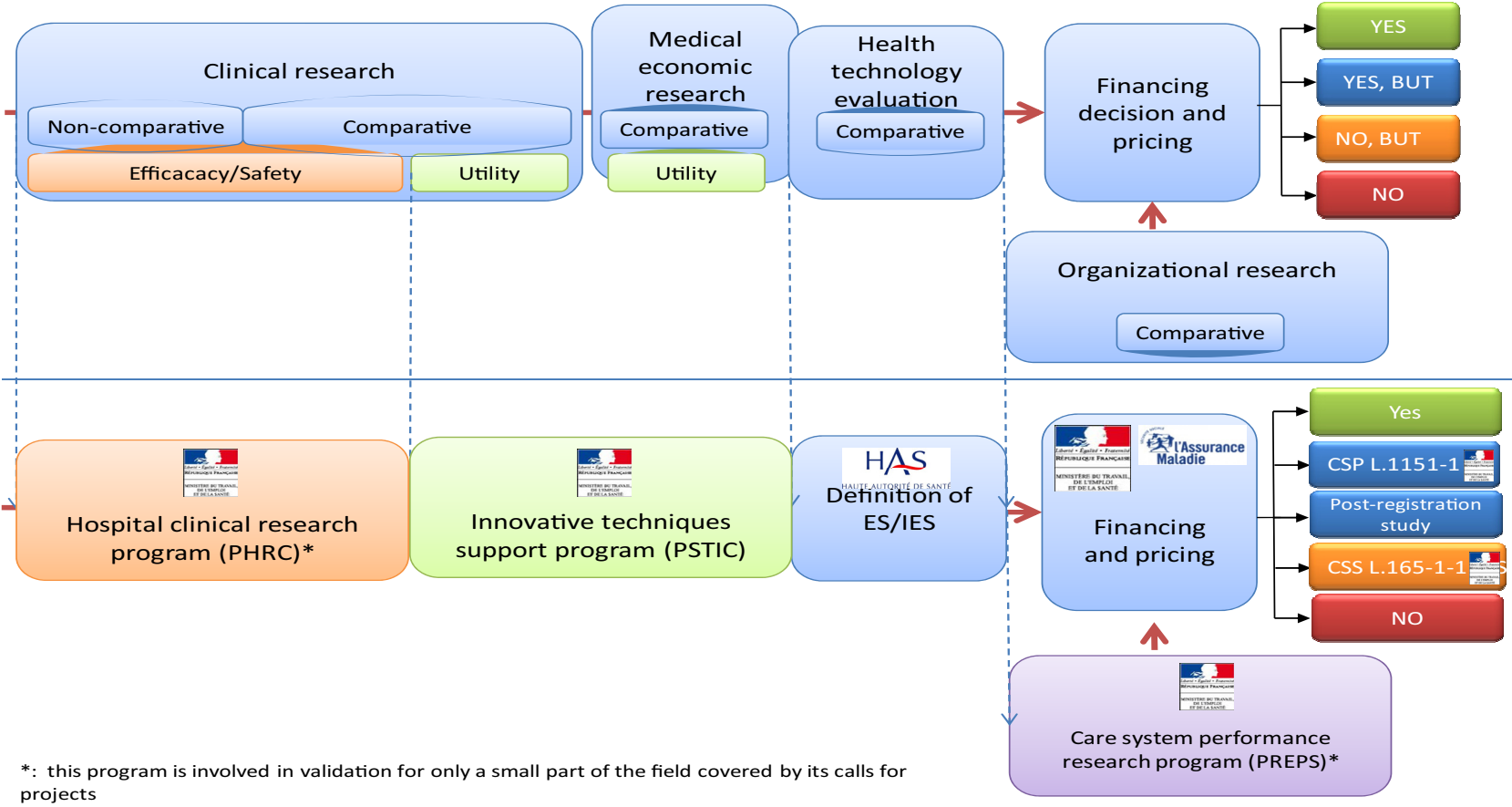

projects

\section{Source: DGOS-PF4}

Fig. 2. Flowchart for innovation in France according to general health service authority (DGOS) programs. With courtesy of Dr. Carbonneil.

Medical economic research is situated upstream of HAS evaluation by association with the STIC program. However, Decree 2012-1116 of October 2, 2012, concerning HAS medical economic missions, comes into application in October 2013 and should clarify the type of economic data required for medical device cover outside of the STIC arrangements.

CSP: Public Health Code (Code de la santé publique); CSS: National Health Insurance Code (Code de la sécurité sociale); DGos: General Health Service Authority (Direction générale de l'offre de soins); ES/IES: expected service/improvement of expected service (service attendu/amélioration du service attendu); HAS: Health Authority (Haute autorité de santé); PHRC: hospital clinical research programm (programme hospitalier de recherche clinique); PSTIC: cost-heavy innovative techniques support programm (programme de soutien aux techniques innovantes et coûteuses); STIC: innovative techniques supports programm (soutien aux techniques innovantes et coûteuses).

nomenclatures. The coding would, however, need to be fully understood and implemented by the health professionals, despite not necessarily being associated with any financing.

It is a difficult subject as it might at least partly hinder free access to intra-GHS financing. It may also seem paradoxical to propose a system of early coding with no systematized temporary financing as a solution to accompany innovation.

Nevertheless, clarity as to the use made of an innovation in France would be a helpful input to assessment of efficacy, usefulness and subsequent financial cover.

Moreover, new provisions are gradually being set up, such as HAS evaluation of certain categories of intra-GHS devices, which may clarify what solutions are available in practice, without, however, determining the whole of the issue, since this measure does not concern procedures.

It was not possible at this point in our reflection to go any further on this complex and sensitive issue, which deserves a round-table of its own.

\section{Limitations and perspectives}

The work of the round-table was limited by a lack of representation of certain partners such as private-sector physicians and small medical firms. Also, although there are obviously some elements in common, issues of disability and telemedicine would have been worth dealing with, but this could not be done for lack of time.

There is also a need for thinking about the evolution of the dataset required in order to obtain financing of a medical device: assessment criteria, internationalization of data, data required for companion biomarkers, and economic data. The round-table's consensus proposals and discussion points should not be seen as palliating a lack of relevant clinical data in the evaluation request file for financing medical procedures and devices.

\section{Conclusion}

The round-table provided in-depth analysis of evaluation and pricing processes for medical devices and associated procedures. 
Points for improvement were highlighted and concrete proposals were formulated.

The discussion points, finally, were very open, seeking to prime reflection so as to achieve more efficient decision processes for the French health system and its patients.

Aknowledgments. Warmest thanks to all participants in round table $\mathrm{N}^{\circ} 1$ of the XXVIII ${ }^{\text {th }}$ Giens Workshops.

\section{Conflicts of interests. None.}

Abbreviations. CCAM: medical procedures classification (classification commune des actes médicaux); CEPS: Health Products Economic Committe (Comité économique des produits de santé); CNEDiMTS: National Medical Device and Health Technology Evaluation Commission (Commission nationale d'évaluation des dispositifs médicaux et des technologies de santé); CSP: Public Health Code (Code de la santé publique); CSS: National Health Insurance Code (Code de la sécurité sociale); DGOS: General Health Service Authority (Direction générale de l'offre de soins); ENCC: common methodology national costs study, a financial study intended to calculate real mean costs per admission-related group for the health establishment, based on the analytic accounts of the sutdy centers (étude nationale des coûts à méthodologie commune); FFR: fractional flow reserve; GHM: diagnosis-related group (groupe homogène de malades); GHS: admission-related group (groupe homogène de séjour); HAS: Health Authority (Haute autorité de santé); HPST: (law) "hospital, patients, health, territory » ([loi] «Hôpital, patients, santé, territoire »); INCa: National Cancer Institue (Institut national du cancer); LPP: list of products and services reimbursed ty the National Health Insurance System (liste des produits et prestations remboursables); NABM: medical biology procedures nomenclature (nomenclature des actes de biologie médicale); NGAP: general professional procedures nomenclature (nomenclature générale des actes professionnels); PHRC: hospital clinical research program (programme hospitalier de recherche clinique); PSTIC: cost-heavy innovative techniques support program (programme de soutien aux techniques innovantes et coûteuses); T2A: health service pricing by procedures (tarification à l'activité); UNCAM: National Union of Health Insurance Offices (Union nationale des caisses d'Assurance maladie).

\section{Annex 1}

To be eligible for the list of products and services reimbursed by the National Health Insurance System (LPP) list of products and services reimbursed by the national health insurance system, a device must be single-use and classifiable under one of the following rubrics:

- Rubric I: Home treatments and equipment, dietary items, dressing items

- Rubric II: Orthoses and external prostheses

- Rubric III: Implantable medical devices

- Rubric IV: Vehicles for the physically disabled

\section{Annex 2}

The Health Products Economic Committee (Comité économique des produits de santé) is an interministerial organization under the joint authority of the Ministers in charge of health, national health insurance and the economy. It sets reimbursement prices for drugs and single-use medical devices and services covered by the national health insurance scheme, and monitors the ensuing expenditure.

The Hospital Admission Council (Conseil de l'hospitalisation) makes recommendations to the Minister regarding health establishment financing policy and national health insurance expenditure objectives for hospital admissions.

\section{References}

1. Article L165-1 du Code de la sécurité sociale. http://www.legifrance.gouv.fr

2. Article L165-11 du Code de la sécurité sociale. http://www.legifrance.gouv.fr

3. Article L165-1-1 du Code de la sécurité sociale. http://www.legifrance.gouv.fr

4. Article L1151-1 du Code de la santé publique. http://www.legifrance.gouv.fr

Correspondence and offprints: Frédérique Debroucker, Medtronic France SAS, 27 quai Alphonse le Gallo, CS 30001, 92513 Boulogne-Billancourt Cedex, France.

E-mail: frederique.debroucker@medtronic.com 